\title{
THE R SPECTRA OF ATOMS AND MOLECULES
}

\author{
M. W. Evans ${ }^{1}, H$. Eckardt $^{2}$ \\ ${ }^{1}$ Civil List (www.webarchive.org.uk, www.aias.us, www.atomicprecision.com, www.et3m.net, \\ www.upitec.org) \\ ${ }^{2}$ AIAS / UPITEC (www.aias.us, www.et3m.net, www.upitec.org)
}

\begin{abstract}
The concept of $R$ spectra of atoms and molecules is developed to give spectral profiles in individual examples. The concept is based on absorption theory with conservation of linear momentum correctly considered for the first time. These considerations extend the Einstein energy equation and rest energy concept to general relativity, the rest mass concept of special relativity becomes the covariant mass of general relativity, defined in terms of the $R$ factor with units of inverse metres squared. Each atomic or molecular transition has its own $R$ spectrum or pattern.
\end{abstract}

Keywords: ECE theory, $R$ theory, $R$ spectra of atoms and molecules.

\section{INTRODUCTION}

In recent work in this series of one hundred and sixty five papers to date [1-10] the Einstein de Broglie equations were tested correctly for the first time using straightforward methods and found to be internally inconsistent to the point of being unworkable in special relativity. This work has been reported in UFT 158 to 164 of this series, published on the ECE websites [11]. Disaster for modern physics has been averted by development of the idea of covariant mass in general relativity as corrected by ECE theory. The covariant mass is defined in terms of the $R$ parameter of the ECE wave equation, a parameter which is based on the concept of covariant mass. Although $R$ was introduced in the earliest papers of this series, its profound significance did not become entirely clear until the failure of the old physics became apparent in papers such as UFT 158 and UFT 159. In these papers it was found that the theory of Compton scattering failed completely if based on special relativity, in that the masses of interacting elementary particles were not constant according to de Broglie Einstein theory properly applied. The foundations of the old physics therefore collapsed, the subject is self consistent only within a narrow context.

General relativity as proposed by Einstein and others in the twentieth century has been known nearly since inception in 1915 to be fundamentally erroneous for several reasons, notably the use of an incorrect symmetry for the geometrical connection.
The theory failed completely with the discovery of whirlpool galaxies, which it cannot describe at all. This is another intellectual disaster for the old physics, one which has been corrected by ECE theory through the use of a more complete geometry that includes torsion as well as curvature. ECE is able to describe the basics of whirlpool galaxies straightforwardly [11] without use of dark matter or non Baconian string theory. The old Einsteinian general relativity was based on a completely arbitrary neglect of spacetime torsion. The latter exists in Riemann geometry and in all developments therefrom [12] such as Cartan geometry or any other valid geometry. It was found in papers such as [11] that the action of the commutator on any tensor in any geometry isolates the geometrical connection. The latter must the refore have the antisymmetry of the commutator.

The crisis for the old physics worsened when it was found that absorption theory had not properly taken into account conservation of linear momentum, and again disaster was averted through the use of $R$, which produces new types of spectra of use in spectral analysis. In Section 2 the theory of $R$ spectra is developed from the scattering angle defined within atoms and molecules by the correct consideration of conservation of linear momentum. These considerations are extended to Raman scattering in Section 2, and in Section 3 some illustrations of $R$ spectra are given in atomic hydrogen and other cases. 


\section{R SPECTRUM IN ATOMIC AND MOLECULAR ABSORPTION}

A scattering angle was defined in the context of atomic absorption by properly considering conservation of momentum [11]:

$$
\cos \theta=\frac{E_{1} E_{2}-E_{0}^{2}}{\left(E_{1}^{2}-E_{0}^{2}\right)^{1 / 2}\left(E_{2}^{2}-E_{0}^{2}\right)^{1 / 2}}
$$

where $E_{1}$ and $E_{2}$ are energy levels of the $\mathrm{H}$ atom and where $E_{0}$ is defined by:

$$
E_{0}=\hbar c R^{1 / 2}
$$

where $R$ is defined by the ECE wave equation [11]:

$$
(\square+R) q_{\mu}^{\alpha}=0
$$

Here $\hbar$ and $c$ are the reduced Planck constant and speed of light respectively, and $q_{\mu}^{\alpha}$ is the Cartan tetrad. For the free electron Eq. (2) reduces to: $E_{00}=m_{0} \mathrm{c}^{2}$

where $m_{0}$ is the mass of the free electron, its mass as given in standards tables. The work from UFT 158 onwards shows that this concept of mass is insufficient, mass has a deeper meaning and the $\mathrm{R}$ concept fulfils this requirement. Whenever the electron is inside an atom or molecule and whenever it interacts with a photon during the process of absorption, Eq. (2) applies. The same concept applies in Compton scattering, when an incoming $X$ ray or gamma ray collides inelastically with an electron in an atom or molecule. The concept of the free electron is an ideal, because it can never be observed without interaction. This fact brings into question what is actually meant by the mass $m_{0}$. For example, one of the experiments used to determine the electron mass in standards laboratories is measurement of the Rydberg constant, but in view of UFT 158 onwards to this paper, the Rydberg constant has been interpreted hitherto without correct consideration of conservation of linear momentum. It was interpreted form the Schroedinger equation, which gives:

$$
R_{\text {Rydberg }}=m_{o} e^{4} / 8 h \in_{o}{ }^{2}
$$

where $\epsilon_{0}$ is the vacuum permittivity that is used in the Coulomb law of the Schroedinger equation. This procedure gives good agreement with experiment, as is well known, but only within a narrow context and in the non relativistic limit of quantum mechanics. It is now known, following UFT 158 onwards, that this is agreement in narrow context. In a broader context the theory fails completely. If a theory fails in one context it must be discarded or developed. This is a fundamental rule of natural philosophy.
We now know that the rest energy $E_{0}$ is a function of $R$, and in general both $E_{0}$ and $R$ vary, they are characteristic of the situation being considered, in this section absorption and Raman scattering. This conclusion is brought about by simple but correct consideration of conservation of linear momentum. In the old atomic theory this was approximated roughly by use of the 1 quantum number as shown [11].

Solving Eq. (1) gives the $R$ spectra for atomic and molecular absorption:

$R=\frac{1}{2 a \hbar^{2} c^{2}}\left(-b \pm\left(b^{2}-4 a c^{\prime}\right)^{1 / 2}\right)$

where:

$a=1-\cos ^{2} \theta$,

$b=\left(E_{1}^{2}+E_{2}^{2}\right) \cos ^{2} \theta-2 E_{1} E_{2}$,

$c^{\prime}=E_{1}^{2} E_{2}^{2}\left(1-\cos ^{2} \theta\right)$.

In general there are two solutions: $R_{+}$(positive b) and $R_{-}$(negative b). The $R$ spectra can be defined as graphs of $R \pm$ against $\theta$ for given $E_{1}$ and $E_{2}$. These are energy levels which can be measured experimentally from atomic or molecular spectra as is well known. The energy levels $E_{1}$ and $E_{2}$ are bound states so are negative valued. Whenever $R$ is complex valued then we adopt the usual rule in physics of using the conjugate product to derive a real value as follows:

$R:=\left(R R^{*}\right)^{1 / 2}$

so:

$$
\begin{aligned}
& R_{+}(\theta)=\left(R_{+} R_{+}{ }^{*}\right)^{1 / 2} \\
& R_{-}(\theta)=\left(R_{-} R_{-}^{*}\right)^{1 / 2}
\end{aligned}
$$

Since $\theta$ is in general unknown, it is varied in the range:

$0 \leq \theta \leq \pi$

and incremented to give plots of $R_{+}(\theta)$ and $R_{-}(\theta)$. These define the $R$ spectra of atomic and molecular absorption and are of great utility in analysis.

Similarly, the $R$ spectra of Raman scattering can be found from Eq. (86) of UFT 162

$R=\frac{1}{2 a \hbar^{2} c^{2}}\left(-b \pm\left(b^{2}-4 a c^{\prime}\right)^{1 / 2}\right)$

where

$$
\begin{aligned}
& \mathrm{a}=1-\cos ^{2} \theta \\
& b=\left(E_{i}^{2}+E_{f}^{2}\right) \cos ^{2} \theta-2 A, \\
& c^{\prime}=A^{2}-E_{i}^{2} E_{f}^{2} \cos ^{2} \theta \\
& A=E_{i} E_{f}-\hbar^{2} \omega \omega^{\prime}(1-\cos \theta) .
\end{aligned}
$$


This equation is found from a very simple initial equation and the method can be greatly developed to more complete types of Raman theory. Here $\omega$ is the incident angular frequency in Raman scattering, and $\omega^{\prime}$ is the scattered angular frequency. In Eq. (13), $\theta$ is the angle of scatter used in the spectrometer. The initial energy level of the electron in the atom or molecule is $E_{i}$ and the final energy level is $E_{f}$. In Eq. (12) a photon collides with an electron in energy level $E_{i}$ of the atom or molecule. The energy is increased to $E_{f}$ of a higher energy orbital, and the photon loses energy to $\hbar \omega^{\prime}$. The photon is scattered from the molecule with this energy. Raman scattering depends on the induced electric dipole moment: $\mu=\alpha E$

where $E$ is the electric field strength of the incoming electromagnetic field and where $\alpha$ is in general an anisotropic polarizability tensor. In the simplest, well known classical theory:

$\alpha=\alpha_{o}+\Delta \alpha \cos \omega^{\prime} t$

where $\varpi^{\prime}$ is a vibrational or rotational frequency of the molecule. The electric field is developed as:

$|E|=E_{o} \cos \omega t$

so:

$\mu(t)=\alpha_{o} E_{o} \cos \omega t+\frac{1}{2} \Delta \alpha E_{o}\left(\cos \left(\omega+\omega^{\prime}\right) t+\cos \left(\omega-\omega^{\prime}\right) t\right)$.

The unshifted frequency is the Rayleigh radiation, the Stokes lines are $\omega-\omega^{\prime}$, and the anti-Stokes lines are $\omega+\omega^{\prime}$.

The $R$ spectra in general are spectra of general relativity unified with quantum mechanics, the above theory is the simplest non-relativistic theory possible, used on the classical level for illustration. Therefore the $R$ spectra give new information not found in the standard theory of Raman or Rayleigh scattering. The conservation of energy in Eq. (12) is:

$E_{f}-E_{i}=\hbar\left(\omega-\omega^{\prime}\right)$

and the conservation of momentum (hitherto unconsidered) is:

$p_{f}-p_{i}=\hbar\left(k-k^{\prime}\right)$.

In elastic Rayleigh scattering or elastic neutron scattering:

$\omega=\omega^{\prime}, k^{2}=k^{\prime 2}$.

The $R$ spectrum for elastic Rayleigh scattering is given by Eq. (43) of UFT 163:

$m=\frac{\hbar \omega}{c^{2}}, R=\left(\frac{m c}{\hbar}\right)^{2}$

SO:
$R=\left(\frac{\omega}{c}\right)^{2}$.

Although this is a simple result, it is a result of general relativity. Therefore, for the first time, general relativity as corrected by ECE theory has been incorporated into the theory of absorption and scattering.

\section{ILLUSTRATIONS OF R SPECTRA IN ABSORPTION PROCESSES}

Some $R$ spectra have been calculated numerically according to Eqs. (6-7). We used atomic units with electron mass $m_{0}=1$ and $c=137.036018$. This avoids instabilities due to widely varying exponents. The first example is the atomic transition $1 \mathrm{~s} \rightarrow 2 \mathrm{p}$ of atomic hydrogen. In Fig. 1 the angular dependence of the square root argument of Eq. (6) is shown. This determines whether the curvature parameter is real or complex. From Fig. 1 we can see that the square root argument varies as a harmonic function and is negative in the whole angular region. Therefore the curvature is complex valued and the average values $R_{+}, R_{-}$according to Eqs. (8-10) have to be used. These are plotted in Fig. 2, showing that the oscillatory structure totally cancels out and the curvature is constant over the full range. This behaviour is valid not only for optical spectra but also for Xray absorption spectra. With increasing energy, the curvature deviates from the constant value near to the borders $\theta=0$ and $\theta=\pi$, see Fig. 3. The deviation is massive, i.e. by several orders of magnitude.

To see the effects for hard X-ray radiation we have studied the range $E_{b} \approx E_{00}$, i.e. the binding energy is near to the rest energy of the electron, the "ultra-relativistic" case. The total energy $E_{l}$ is defined by

$E_{1}=E_{00}-E_{b}$.

For $E_{b}=0.95 E_{00}$ (Fig. 4), the region at both ends has broadened significantly but the complex-valued constant middle region is still there. Both curvatures

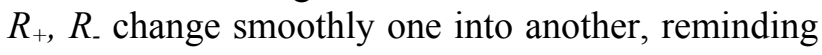
to the behaviour of complex analytic functions. For $E_{b}=E_{00}$ (which means vanishing total energy) we obtain a very simple $R$ structure: a zero line and a parabola. The zero line indicates no curvature, meaning that the electron has been destroyed.

We can even extend the investigation to negative total energies, although this case is considered superfluous in ECE theory because there is no need for assuming a Dirac sea of electrons. From Fig. 6 (for $E_{b}=1.05 E_{00}$ ) we can see that the zero curvature line then disappears, and curvature becomes present 
again. Finally we consider the Raman spectra described by Eqs. (12-13).

\section{CONCLUSION}

Results show that the $R$ parameters are independent of angle in the same way as shown in Fig. 1. This can easily be seen from the lowermost part of Eq. (13). The frequencies $\omega$, enter the A parameter only. Because of $\hbar \omega\left\langle\left\langle E_{00}, \hbar \omega\left\langle\left\langle E_{00}\right.\right.\right.\right.$ in Raman spectroscopy, A does not significantly depend on the frequencies. Therefore $R$ behaves very similar to the absorption spectra discussed before, leading to no angular dependence in the low energy range. In total all these low-energy spectra are independent of the scattering angle, as far as no quantum orbitals are considered which would go beyond the scope of this paper.

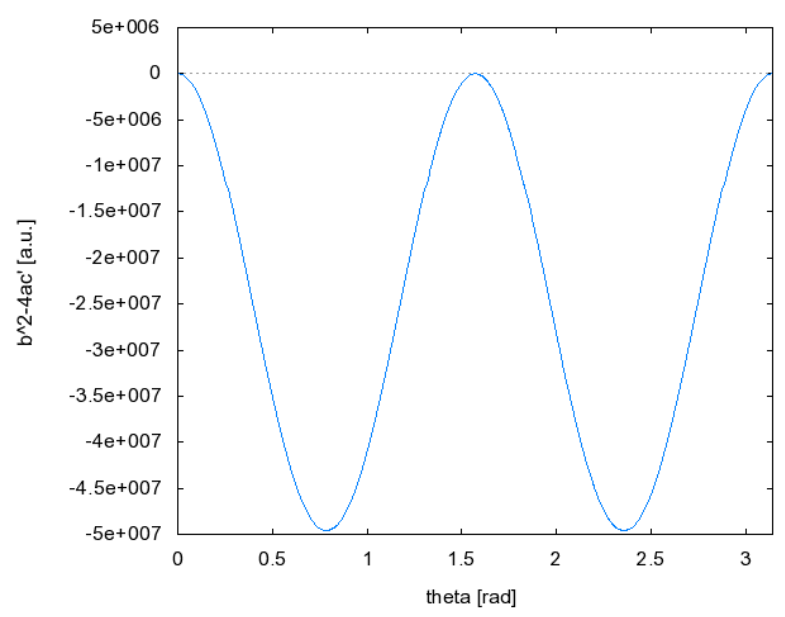

Figure 1. Angular dependence of square root argument in Eq. (6) for hydrogen $1 s \rightarrow 2 p$ transition.

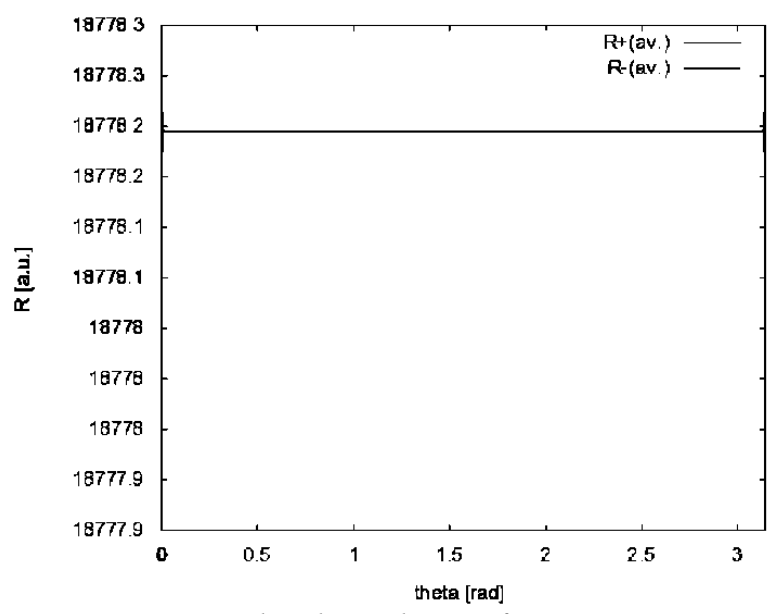

Figure 2. Angular dependence of average curvature parameters $R_{+}, R_{-}$for hydrogen $1 s \rightarrow 2 p$ transition.

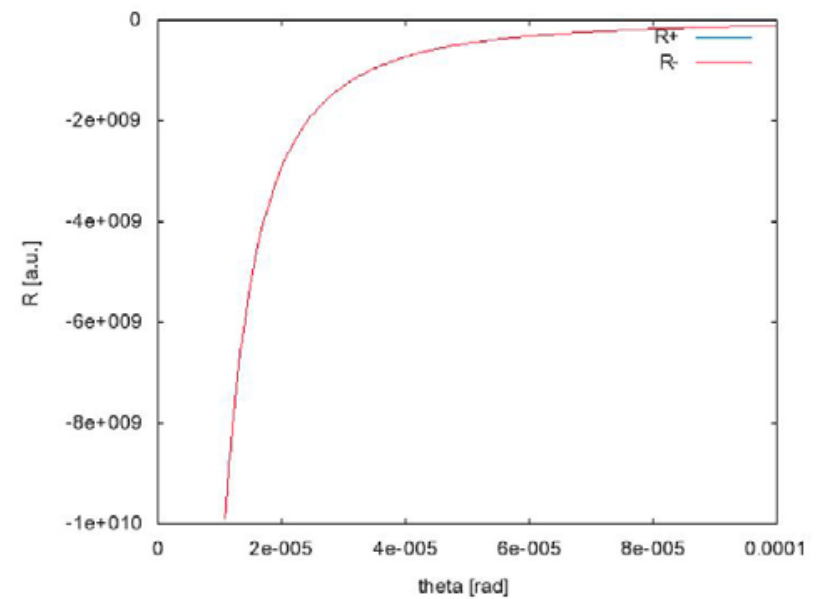

Figure 3. Angular dependence of curvature parameter $R_{-}$ for small angles $\theta, X$-ray absorption of $C a 1 s$ state (4038.5 eV).

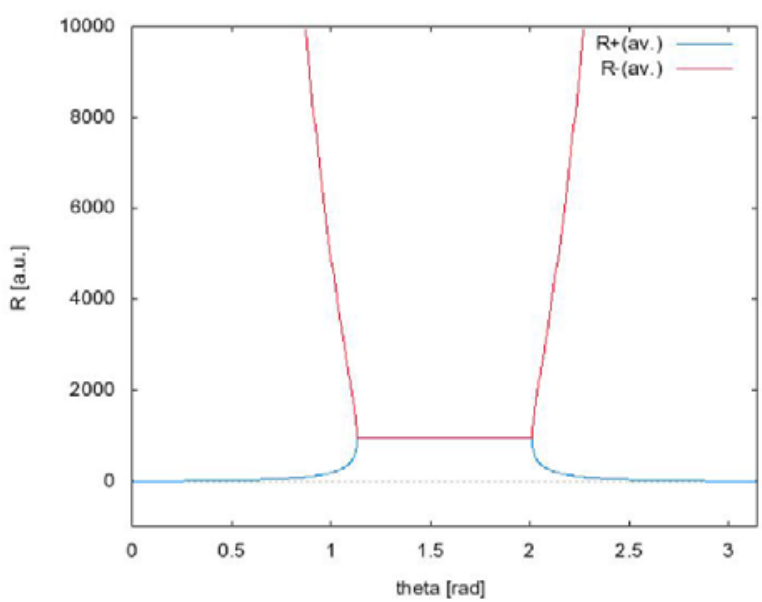

Figure 4. Angular dependence of average curvature parameters $R_{+}, R$ for small angles $\theta, \Delta E=0.95 E_{00}$.

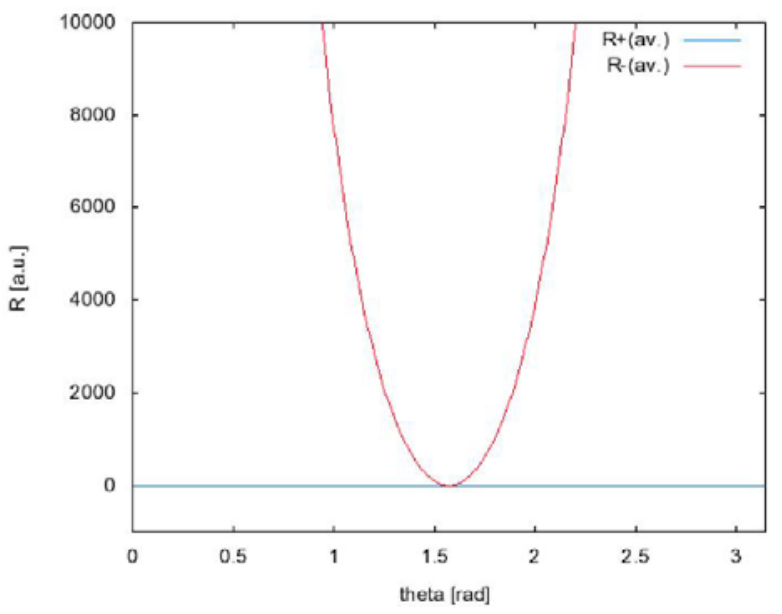

Figure 5. Angular dependence of average curvature parameters $R_{+}, R$ for small angles $\theta, \Delta E=E_{00}$. 


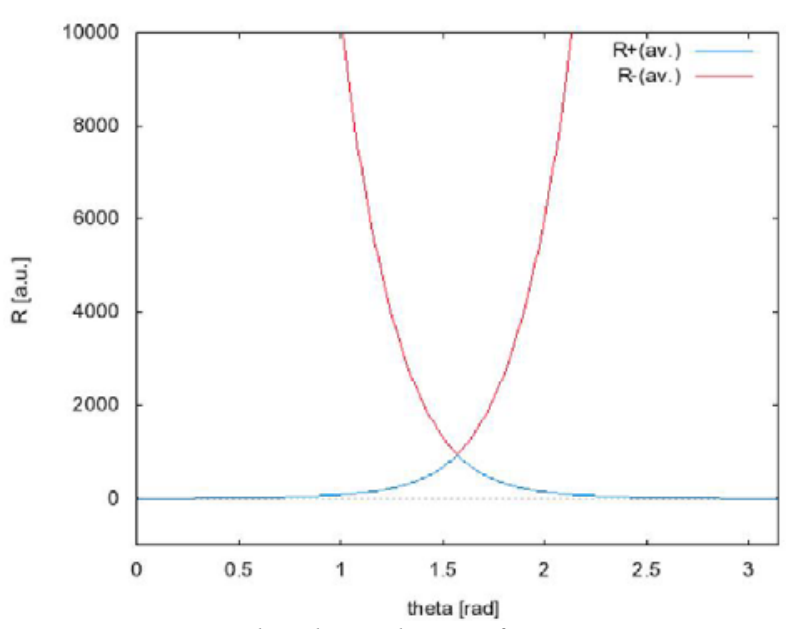

Figure 6. Angular dependence of average curvature parameters $R_{+}, R_{-}$for small angles $\theta, \Delta E=1.05 E_{00}$.

\section{ACKNOWLEDGMENTS}

The British Government is thanked for a Civil List Pension and other high honours in recognition of ECE theory and other work. The AIAS working group is thanked for many interesting discussions. Alex Hill and colleagues are thanked for voluntary typesetting and numerous successful translations into Spanish, David Burleigh for voluntary posting on www.aias.us, and Simon Clifford for voluntary help with broadcasting.

\section{REFERENCES}

[1] M. W. Evans et al., Generally Covariant Unified Field Theory (Abramis 2005 onwards), in seven volumes to date.
[2] M. W. Evans, S. Crothers, H. Eckardt and K. Pendergast, Criticisms of the Einstein Field Equation (Abramis in press, preprint on www.aias.us).

[3] M. W. Evans, H. Eckardt and D. W. Lindstrom, Applications of ECE Theory to Hydrogen Bonding (Serbian Academy of Sciences, 2010).

[4] K. Pendergast, The Life of Myron Evans (Abramis in press, preprint on www.aias.us).

[5] L. Felker, The Evans Equations of Unified Field Theory (Abramis 2007, Spanish translation on www.aias.us).

[6] M. W. Evans et al., the Omnia Opera of www.aias.us.

[7] M. W. Evans and J.-P. Vigier, The Enigmatic Photon (Kluwer, Dordrecht, 1994 to 2002) in five volumes available in the Omnia Opera of www.aias.us.

[8] M. W. Evans and L. B. Crowell, Classical and Quantum Electrodynamics and the B(3) Field (World Scientific, 2001).

[9] M. W. Evans and A. A. Hasanein, The Photomagneton in Quantum Field Theory (World Scientific, 1994).

[10] M. W. Evans and S. Kielich (eds.), Modern Non-Linear Optics (Wiley first and second editions, 1992, 1993, 1997, 2001 and e book editions).

[11] The ECE websites www.aias.us (archived in the National Library of Wales and British web archives), www.et3m.net, www.upitec.org.

[12] S. P. Carroll, Spacetime and Geometry: an Introduction to General Relativity (Addison Wesley, New York, 2004).

\section{R СПЕКТРИ АТОМА И МОЛЕКУЛА}

Сажетак: Концепт R спектра атома и молекула развијен је за добијање спектралних профила у појединачним примјерима. Концепт је развијен на теорији апсорпције, са одржањем линеарног момента који је овдје по први пут коректно размотрен. Ова разматрања проширују Ајнштајнову енергетску једначину и концепт енергије мировања на општу релативност, концепт масе мировања из специјалне теорије релативности постаје коваријантна маса опште релативности, дефинисана преко R фактора у јединицама м $^{-2}$. Сваки атомски или молекуларни прелаз има властити R спектар тј. узорак.

Кључне ријечи: ECE теорија, R теорија, R спектри атома и молекула. 